\title{
Planar SOFC system modelling and simulation including a 3D stack module
}

\author{
Amirpiran Amiri ${ }^{1}$, Periasamy Vijay ${ }^{1}$, Moses O. Tadé ${ }^{* 1}$, Khaliq Ahmed ${ }^{1,2}$, Gordon D. Ingram ${ }^{1}$, Vishnu \\ Pareek $^{1}$, Ranjeet Utikar ${ }^{1}$ \\ ${ }^{1}$ Centre for Process Systems Computations, Department of Chemical Engineering, Curtin University, \\ GPO Box U1987, Perth WA 6845 \\ ${ }^{2}$ Ceramic Fuel Cells Ltd., Noble Park, Victoria 3174, Australia \\ "Corresponding Author. Telephone: +61-8-9266-7581. Fax: +61-8-9266-2681. Email: \\ m.o.tade@curtin.edu.au
}

\begin{abstract}
A solid oxide fuel cell (SOFC) system consists of a fuel cell stack with its auxiliary components. Modelling an entire SOFC system can be simplified by employing standard process flowsheeting software. However, no in-built SOFC module exists within any of the commercial flowsheet simulators. In Amiri et al. (Comput. Chem. Eng., 2015, 78:10-23), a rigorous SOFC module was developed to fill this gap. That work outlined a multi-scale approach to SOFC modelling and presented analyses at compartment, channel and cell scales. The current work extends the approach to stack and system scales. Two case studies were conducted on a simulated multilayer, planar SOFC stack with its balance of plant $(\mathrm{BoP})$ components. Firstly, the effect of flow maldistribution in the stack manifold on the SOFC's internal variables was examined. Secondly, the interaction between the stack and the BoP was investigated through the effect of recycling depleted fuel. The results showed that anode gas recycling could be used for managing the gradients within the stack, while also improving fuel utilisation and water management.
\end{abstract}

Key words: SOFC, system, stack, balance of plant, Aspen Plus 


\section{Introduction}

Fuel cells are electrochemical reactors that convert chemical energy directly into electrical energy, which is in contrast to conventional power plants where chemical energy is first converted to mechanical energy before it is converted into electrical energy. The key advantages of this technology are not only high efficiency and low emission of pollutant gases, but also its diversity of fuel sources, particularly renewables, such as biogas and ethanol. Nevertheless, the commercialization of fuel cell technology has been hindered by several technical challenges. Modelling and simulation approaches will play a central role in overcoming some of these barriers. Modelling tools reduce the costs and risks of experimental investigations through screening the more feasible and reliable cases. Further, material performance analysis, fluid flow design, system energy analysis, fuel pre- and post-processing analysis and optimization, durability assessment and system interactions are some of the tasks that can benefit from a reliable and flexible model.

In the last two decades, the development and refinement of detailed mathematical models of fuel cells - a multidisciplinary endeavour - has increasingly received attention from researchers. In the more fundamental studies, the main goal is to understand and capture the cell's internal operational behaviour, transport phenomena and reaction aspects. These are of vital importance in exploring the fundamental mechanisms and providing deep insights into the small scale behaviour of a fuel cell that can be used in higher scale models. Typical of these studies are Nikooyeh et al. (2007), Iwata et al. (2000), Andersson et al. (2010) and Aguiar et al. (2004). At the larger stack and system scales, engineering aspects of optimization, design and analysis of the system have been studied (Aguiar et al., 2008; Di Carlo et al., 2013; Ang et al., 2011; Yan et al., 2013; Burt et al., 2004; Secanell et al., 2011; Riensche et al., 1998a,b; Liese and Gemmen, 2005; Braun, 2010; Gandiglio et al., 2014). In these works, cell-to-cell and/or stack-to-BoP interactions are the modelling focus, resulting in an integrated analysis of all the unit operations involved. Furthermore, energy and cost analyses of the system, which are necessary for commercialization, are mainly based on stack and system level models. The more BoP components, chemical species, reactions and transport phenomena involved, the more complicated the system of equations that must be dealt with. Obviously this increases the complexity of the model, which is not always desirable. Further, the process flowsheet may vary depending on the application area of the fuel cell system. If a dedicated software package for fuel cells is created, any alteration in the process units or the flowsheet means that the model equations and software may need to be changed. This complexity can be avoided by implementing a flexible fuel cell model within a general process simulator. Such an approach minimizes the work needed to simulate the standard unit operations that form the BoP, and also facilitates making small changes, like to the species present, and large changes, such as reconfiguring the entire flowsheet. Changes to 
the fuel cell and stack can be done independently, thereby facilitating the simulation, analysis and optimization of the process.

Fuel cell system modelling in a process simulator, such as Aspen Plus, has been undertaken in several previous studies. Zhang et al. (2005) created a SOFC system simulation by using inbuilt reactor modules. FORTRAN programming and data post-processing subsequently enabled the authors to simulate a tubular SOFC plant that was validated against a $100 \mathrm{~kW}$ SiemensWestinghouse SOFC stack. Ameri and Mohammadi (2011) used a similar methodology to simulate a SOFC integrated with a gas turbine. Moreover, Kivisaari et al. (2002) and Doherty et al. (2010) used Aspen Plus to model a molten carbonate fuel cell that was fuelled by gasification process products. In another work, Kivisaari et al. (2001) compared the application of three process flowsheeting packages, Design-II, Aspen Plus and Spence, for fuel cell system simulation. They found that, in spite of good agreement of the overall results, significant differences between the packages became apparent on more detailed examination.

The majority of previous studies have used the simulator's inbuilt reactor modules to approximate the fuel cell. However data post-processing was also inevitably used to transform the simulator results into those representing a simplified lumped electrochemical reactor. In spite of the simplicity of this approach, there are some serious deficiencies. Table 1 compares some of the features of previous works to the current study. Some of the limitations compared to the current approach are outlined in the following. First, the parameters and variables of the fuel cell are limited to userdefined equations added to the flowsheet. Second, the bidirectional interaction of the fuel cell and the rest of the process is not effectively and systematically implemented. Third, the fuel cell's internal reaction and flow phenomena are often not included appropriately, or in some cases not included at all. Fourth, the spatial distributions of a cell's internal variables, which are influenced by BoP parameters, are not captured, but they are vital for the temperature and fuel management of the stack. Fifth, the fuel and oxidant flow patterns in the cell are not considered. Finally, stacking related issues, manifold flow distribution effects for instance, are neglected. In the cases in which a userdefined reactor is developed and used, the majority of the abovementioned flaws are still present. Most of the deficiencies mentioned here have been addressed in this paper (Table 1), the most important of which is the influence of BoP parameters on the cells' internal, spatially distributed variables. This is a key aspect of the current work.

It should be noted that the configuration of the fuel cell reactor is also an important consideration in modelling. Even though a fuel cell reactor could be approximated by ideal reactor models, such as the Plug Flow Reactor (PFR) or Continuous Stirred Tank Reactor (CSTR) under specific conditions, in practice a fuel cell reactor's performance may fall in between these two ideal models depending 
on the hydrodynamics. A flexible model is, therefore, required to account for ideal and non-ideal flow behaviour. The CSTR-in-series methodology is sufficiently general and flexible to address this requirement. Therefore, another contribution of the modelling approach proposed in this work is to enable the user to simulate a planar SOFC reactor as a PFR, CSTR or a more complex reactor according to the flow regime of interest, along with the BoP. Analysis of residence time distribution data can provide information about the number of consecutive CSTRs needed.

\section{Modelling and simulation methodology and input parameters}

Since fuel cell design and operation possess a multi-scale nature, its behaviour should be described through a multi-physics, multi-scale modelling strategy. However, unnecessary complexity in the final model must be avoided. The aim of the current study is to conceive and implement a multiscale framework for modelling a SOFC system within a well-established process flowsheeting environment such as Aspen Plus or Aspen Hysys. Figure 1 shows the modelling framework that was proposed and partly implemented in Amiri et al. (2015). The interested reader may refer to that paper where the authors describe and analyse compartment, channel and cell scale SOFC models using the proposed framework. In contrast, the focus of this paper is on multi-cell stack and system level modelling and simulation. 


\section{Stack and system modelling and simulation}

A SOFC channel is assembled from a series of compartment blocks created in Aspen Custom Modeller (Amiri et al., 2015). The conservation and constitutive equations for a single compartment were adapted from Hosseini et al. (2010) and Danilov et al. (2011). A cell model is constructed by combining channels as the repeating elements. Consequently, assembling a SOFC stack is straightforward, with the cells being used as repeating units.

It should be noted that different configurations of compartment models can be created and saved as templates in a simulator modelling library for different scales of interest. For instance, at the compartment scale, the modelling block could be extended for an external reforming or internal reforming SOFC. The latter could use direct internal reforming or indirect internal reforming. Moreover, for the channels, different fuel-oxidant flow patterns can be constructed by appropriately linking the material streams. Accordingly, a variety of cells with different flow patterns can be created, including co-flow, cross-flow and counter-flow cells, by joining channels in the required configuration. At the stack level, cells might be configured in parallel, series or any other practical or theoretical arrangement. Further, the flow configuration of the fuel and air streams in a stack's manifold can be easily implemented by connecting the material streams between cells as required.

A simulation at the stack and system levels of a SOFC plant has been constructed and is shown in Figure 2. The following assumptions were used to develop the simulation.

- By default, the air and fuel are uniformly distributed through the cell manifold. However, maldistribution of the fuel flow is investigated in the stack analysis section.

- The stack operates adiabatically: perfect insulation from the environment is assumed.

- A four-cell, layered SOFC stack is considered. Even though the number of cells may be markedly higher in practice, depending on the system's required power output, a four-cell stack is reasonable for simulation investigations and it is common in some of the recent experimental demonstration rigs (Bertoldi et al., 2008; Yuan et al., 2012). The limited number of cells reduces the model's computational time/costs and is more convenient for validation purposes from the standpoint of having experimental data available.

- Heat transfer between cells in the stack is neglected. This is a reasonable assumption according to the justification given by Nikooyeh et al. (2007).

- Within each cell, changes in the vertical $(z)$ direction are negligible; more importantly, variations in lateral $x$ and $y$ directions are considered.

- External fuel reforming is used for the hydrogen supply to the fuel cell anode. The mixture properties, however, are updated according to the local conditions, of composition and temperature, inside the channels of the fuel cell stack. 
- The voltage is constant and uniform over all the stack's compartments and cells. The Open Circuit Voltage (OCV) is calculated based on the Nernst equation using the estimated temperatures and compositions in each simulation run.

Figure 2 shows the process flow diagram of a typical SOFC plant as implemented in Aspen Plus. Because of the flexibility of the approach developed in this article, the unit operations involved in the plant and the way they interact may be easily varied based on a particular process' goals and design. Nevertheless, a fuel cell system generally consists of several subsystems including the electrochemical fuel cell reactor, fuel and air pre-processing, depleted fuel post-processing, and possibly gas turbines in the case of a hybrid power plant.

For flowsheet simulation purposes, the fuel cell reactor, in the form of a SOFC stack, has been implemented as a user-defined subsystem, while other BoP components are selected from Aspen Plus' standard model library. Based on the nature of the reactions that occur in each auxiliary reactor in the BoP, an appropriate module must be chosen or developed. For instance, Di Carlo et al. (2013) presented a user-defined fluidized bed reactor for a gasification unit coupled with a SOFC in a hybrid plant. In that work, a natural gas feed mainly consisting of methane was used as the feedstock of the stack after passing through a reformation process to create synthesis gas. The Methane-SteamReforming (MSR) and Water-Gas-Shift (WGS) reactions were assumed to reach chemical and thermal equilibrium. The combustion reactions, in contrast, were modelled as close to complete conversion. Since the SOFC stack is the main focus of the current work, the auxiliary reactors in Figure 2 are simulated based on these simplifying assumptions, enabling us to use inbuilt Aspen Plus modules. Accordingly, the gas pre-reformer and residual gas burner (afterburner) units are approximated by equilibrium and stoichiometric reactors that are simulated using Aspen Plus RGibbs and RStoic blocks, respectively. While the afterburner is assumed to be adiabatic, the reformer energy makeup is assumed to be provided externally by recovering energy from the process downstream to keep the endothermic reaction and the reaction products at a constant temperature. The amount of energy required varies nonlinearly with the operational conditions such as feed flow rate, temperature and composition, as well as the reactor's pressure. The reformer heating jacket is simulated using a standard Heater block in Aspen Plus. For further details on the simulation of BoP components in Aspen Plus, the reader is referred to Zhang et al. (2005). The simulation input data are listed in Table 2. 


\section{Results and discussion}

In addition to providing the overall system's mass and energy balances and the conditions inside the stack, the proposed model serves as a detailed, but user-friendly, tool for operational analysis, thermal integration, flowsheet reconfiguration, economic assessment and process optimization. In the following sections, three system-level evaluations are carried out:

1. Compartments' interactions: the influence of the reformer operation on a single cell's behaviour;

2. Stacking issues: the role of flow maldistribution in the manifold on the cell's and stack's spatially distributed variables;

3. System characteristics: the effect of the recycle stream flow rate on the stack's internal profiles.

\section{Cell analysis: Effect of reformer temperature and anode gas recycling (AGR)}

Current density, temperature, hydrogen concentration and OCV are interdependent variables; their spatial profiles inside the cell affect its electrical and thermal performance. Any external disturbance caused by the BoP may influence the electrochemical reaction and transport rates inside the cell, and subsequently the abovementioned distributed variables, in a highly nonlinear manner. A key objective of the plant modelling approach presented in this article is to capture the impact of changes in the BoP parameters on a cell's internal, spatially distributed variables.

As a pivotal unit operation in a SOFC process plant, the external reformer/pre-reformer influences the plant's overall performance and also the cell's internal spatial gradients. The latter can be explained by the changes in the stack feed's temperature and composition resulting from changes in the reformation process. The fuel reforming unit itself is significantly influenced by various operating parameters including its feedstock composition, steam to carbon ratio, pressure and temperature.

Furthermore, recycling of the depleted fuel back to the process upstream (Stream 11 of Figure 2) may influence the plant's operation in different ways. First of all, the total circulating mass inside the recycle loop increases, leading to higher pressure drops. Secondly, the recycle stream delivers a portion of the valuable unconverted reactants, including syngas $\left(\mathrm{H}_{2}, \mathrm{CO}\right), \mathrm{CO}_{2}$, and potentially methane, mixed with undesired species, such as $\mathrm{N}_{2}$, from downstream to upstream, thereby altering the reformer's - and subsequently the SOFC stack's - feed composition and quality, for example, its hydrogen content. Thirdly, the enthalpy of the mixture fed to the reformer increases due to the elevated temperature of the recycled materials. This may improve the rate of endothermic reactions that take place in the reformer and/or reduce the amount of energy make-up needed for this unit. Fourthly, the steam to carbon ratio $(\mathrm{S} / \mathrm{C})$ in the feed of the reformer will change. The S/C ratio subsequently influences the MSR and WGS reactions' progress and, more importantly, the likelihood 
of carbon deposition in internal and external reformers. All the abovementioned operational consequences of recycling are not necessarily beneficial for the process. The effectiveness of AGR on the process' thermal and electrical efficiencies has been investigated before and is outside the scope of this work. However, AGR's impact on the reformer and on the cell's internal spatial gradients is a focus of this paper, in contrast to analysis of Nikooyeh et al. (2007) in which the role of the reformer is not considered. From the perspective of managing a cell's internal gradients, it might be advantageous to operate within a certain range of recycle flow rates, while recycling might be ineffective or even disadvantageous outside that optimum range. Therefore, an extensive and critical analysis of overall plant performance, along with profiles of the cell's internal distributed variables, for varying recycle flow rates would allow us to determine an effective operating envelope for this key system scale parameter. This is not a straightforward task. It requires a detailed simulation approach, such as the one outlined earlier, that accounts for the cell's and BoP's physicochemical processes, and the interactions of all the process units.

In the following, the role of anode gas recycling on the cell's distributed parameters is investigated for two reformer temperature conditions, Case A: $T=973 \mathrm{~K}$ and Case B: $T=1073 \mathrm{~K}$. The recycle fraction $\left(R_{f}\right)$ is defined as the fraction of stack's outlet stream that is recirculated. Note that an isothermal reformation process is assumed here, thus the stack's inlet temperature and composition are affected by the reformer temperature. The energy demand of the endothermic reaction is estimated for each new condition ( $T$ and $R_{f}$ ) and is provided from burner flue gases to keep the reformer at a constant temperature.

The results of this analysis are shown in Figures 3-5. In these figures, a normalised cell length of zero corresponds to the fresh fuel inlet and a normalised length of one refers to the depleted fuel outlet. Comparing the variable profiles in the fuel flow direction for moderate and high temperature reformers reveals the significant impact of reforming temperature, and hence the stack's feed temperature, on the observed profiles. Even though the temperature profile trends in Figure 3 are almost the same for both reformer temperatures and for all $R_{f}$ values, a few points should be noted. In both cases the temperature gradient changes due to change in hydrogen mole fraction, which can be seen in Figure 4. Further, the average temperature for a given $R_{f}$ is higher in Case B compared to Case A by about $110 \mathrm{~K}$. This can be explained based on the higher inlet temperature, about $100 \mathrm{~K}$ higher, and consequently the improved internal reaction rate in Case B. The latter is supported by the current density profiles, where the higher current generation indicates greater reaction progress (Figure 5). Moreover, the temperature gradient is slightly higher for Case B because of the higher reaction heat generation along the fuel path. In spite of the higher average hydrogen concentration in Case A (Figure $4 \mathrm{a}$ ), the average temperature for a given $R_{f}$ remains lower than that of corresponding condition in Case B (Figure 4b). It, however, cannot necessarily be concluded that the reaction is absolutely temperature controlled rather than reactant controlled in this range of operation. This is supported by 
at least two reasons. First, the temperature gradient decreases in the last $25 \%$ of the cell length, where the $\mathrm{H}_{2}$ concentration reaches its minimum. Second, the current density profile shows nonlinearity, which indicates an interacting role for both temperature and reactant concentration. This is examined in more detail later in this section. The reformer performance as a function of $R_{f}$ can also be analysed based on the hydrogen purity in the reformate. Our analysis shows this dependency is greater for $R_{f}<$ 0.5. For instance, the hydrogen mole fraction in the reformate for $R_{f}=0.1$ is 0.62 and 0.67 for Cases A and B, respectively, while these fractions reduce to 0.56 and 0.57 when $\underline{R}_{f}=0.5$.

Higher $R_{f}$ values offer flatter hydrogen profiles for both Cases $\mathrm{A}$ and $\mathrm{B}$, with the influence being more significant in Case A. In Case $\mathrm{B}$, compared to Case $\mathrm{A}$ and for the same $R_{f}$ condition, the hydrogen consumption, is higher due to the higher average temperature and hence the promoted autothermal reaction. The hydrogen consumption also can be monitored through the drawn current profiles shown in Figure 5. This explains the observed higher gradient in the hydrogen profile in Case B compared to Case A. Also, the cell's anode outlet stream becomes depleted in hydrogen, while it is enriched with water. Therefore, recycling of such a depleted anode off gas upstream causes a dilution effect in the reformer and the stack feed, which can be seen particularly in Figure 4(b). The average hydrogen mole fraction increases with $R_{f}$ in Case $\mathrm{A}$, while it decreases in Case $\mathrm{B}$, which is due to the different quality of the anode stream in these cases.

Current density profiles are different in Cases A and B due to differences in the temperature and hydrogen distributions. Moreover, $R_{f}$ has a significant positive impact on the average current density in the two cases (Figure 5). For Case A, the current density generation benefits from higher temperature and hydrogen concentration by increasing $R_{f}$. It should be noted that this influence is mutual, as the higher current improves the reaction progress, which results in a temperature rise. The current production seems to be mostly dominated by temperature, particularly in first $75 \%$ of the fuel path length, where the $\mathrm{H}_{2}$ mole fraction does not drop below 0.4 . The matter of reactant availability changing with $R_{f}$ is not that important for Case A. In case B, however, the importance of reactant concentration is more apparent, through its impact on the current profile throughout the cell's length and especially for lower $R_{f}$ values where current generation may drop suddenly in spite of the high temperature. Furthermore, the more uniform hydrogen profile at high $R_{f}$ values contributes to more homogeneous current generation as can be seen in Figure 5(b). 


\section{Stack analysis: Effect of manifold maldistribution}

Flow distribution in the manifold plays a significant role in causing the gradients along the stacking direction in a SOFC (Yuan, 2008). One of the features of the current work, in contrast to those mentioned in Table 1, is to account for fuel and oxidant flow distributions along the stacking direction. This enables us to easily investigate the effect of a malfunction in the stack's manifold on the overall performance of a multilayer SOFC and its internal spatially distributed variables.

The flow characteristics in a stack's manifold with complicated geometries and under flow regimes from laminar to turbulent can be predicted by computational fluid dynamics (CFD) tools (Park and Bae, 2011). It should be noted that Aspen Plus and a CFD simulator, such as FLUENT, can be integrated through the CAPE-OPEN interface (Zitney et al., 2004; Zitney, 2006). Accordingly, the modelling roadmap we developed earlier in Amiri et al. (2015) and in this work can potentially be enriched through the use of CFD facilities. Nevertheless, in order to maintain simplicity of the current approach whilst not completely neglecting the manifold hydrodynamics, a correlation for flow distribution in a manifold has been incorporated into the stack simulation. The two main goals of following this approach were (i) to begin to implement cell stacking issues in a process flowsheet and (ii) to investigate the effects of BoP changes on gradients along a stack's height (the $z$ direction indicated in Figure 2).

Due to their importance in many industrial processes, correlations for estimation of flow distributuons in manifold systems have received significant attention (Wang, 2008; Wang, 2011). In this study, a progressively increasing profile for fuel flow in the stacking direction is utilised based on the following equation (Yuan, 2008):

$$
f^{n}=\bar{f}\left(\frac{2 d_{\text {stack }}}{\left(n_{\text {stack }}-1\right)}(n-1)+\left(1-d_{\text {stack }}\right)\right)
$$

where $f^{n}$ and $\bar{f}$ are the cell $n$ flow rate and the mean flow rate of fuel in the stack, respectively; $d_{\text {stack }}$ is the deviation factor in the stacking direction; and $n_{\text {stack }}$ is the total number of cells. The deviation factor is defined as half the difference of the minimum and maximum flow rates divided by mean flow rate, which is assumed to be 0.5 (Yuan, 2008). Based on equation (1), the flow fractions for the fuel splitter are $0.125,0.208,0.292$ and 0.375 for Cell \#1 (top cell in stack) through to Cell \#4 (bottom cell in stack). Note that equation (1) produces a linear distribution of the fuel flow.

Figure 6 shows temperature, current density and $\mathrm{H}_{2}$ concentration distributions in the $x$ direction. Since the cell's flow pattern is co-flow, there are no changes in the $y$ direction.

Even though the temperature gradient along the cell's length $\left(\partial T_{x}\right)$ is a minimum for the cell with the lowest fuel rate (Cell \#1), the largest current density $\left(\partial I_{x}\right)$ and $\mathrm{H}_{2}$ fraction $\left(\partial H_{x}\right)$ changes are observed 
for this cell. Further, the average current density and $\mathrm{H}_{2}$ fraction are also a minimum. Reduction in the fuel flow rate, which can be observed by comparing Cells \#1 through \#4, therefore, has two opposing impacts on the cell performance that must be considered and traded-off in an optimisation analysis.

Fuel maldistribution in the stack's manifold has two main influences on the current density profile (Figure 6c). Firstly, it causes a variation in the current distribution in the $z$ direction $\left(\partial I_{z}\right)$, which is along the stack's height. Secondly, it shifts the current peak in the $x$ direction. Both of these consequences are disadvantageous for operating a stack so that the current density is as uniform as possible.

The effect of fuel distribution on the temperature gradients in the stack's $z$ direction $\left(\partial T_{z}\right)$ may also be observed. It complements the temperature gradient information in the other directions, $\partial T_{x}$ and $\partial T_{y}$. Minimising $\partial T_{z}$ is an objective for the thermal management of a SOFC. As can be seen in Figure 6(a), different layers show very similar temperatures for almost half of the cell's length $(x<0.5)$, with differences becoming larger near the cell's exit. This observation can be explained by the availability of the reactant (see the $\mathrm{H}_{2}$ profile) and consequently the different amount of heat generated through the exothermic electrochemical reaction.

While the difference in fuel flow rate between the adjacent stack layers is the same (a linear change), there is a nonlinear impact on the stack's internal distributed variables. The local $\partial T_{z}, \partial I_{z}$ and $\partial H_{z}$ gradients, therefore, are not equal for all $x$. Further, $\partial T_{z}$ and $\partial I_{z}$ at a particular $x$ location are different for different adjacent layers of the stack; for example, Cells \#1 and \#2 (upper half of stack) compared to Cells \#3 and \#4 (lower half of stack) as can be seen in Figure 7, which shows the gradients in the stacking direction, $z$. The gradient profiles are clearly different for the upper and lower halves of the stack. The upper portion receives less fuel than the lower half. Accordingly, it can be concluded that a manifold flow malfunction has a higher impact on stack gradients in zones with lower fuel rates. Another interesting point is that the maximum current gradient occurs where the temperature and hydrogen gradients are at their maximum, not where the current peaks appear. 


\section{System analysis: Effect of depleted fuel recycling on the stack's profiles}

Perfectly uniform current density and temperatures profiles are impossible to attain in practice in a SOFC stack, but minimising the gradients of these key variables in all three dimensions is always of interest. Minimising current density gradients reduces current density hotspots and hence it avoids localised high fuel utilisation and, in the extreme case, fuel starvation and anode oxidation. Similarly, minimising temperature gradients decreases thermal stresses. To extend the system level analysis, the effect of recycle fraction $R_{f}$ on the internal SOFC profiles in the stacking direction are explored. The results are presented in Figure 8. Interpretation of these profiles is a complicated, interconnected task - it cannot be carried out independently.

Figure 8(a) shows the average temperature for individual cells and also the temperature gradient in the stacking direction $\left(\partial T_{z}\right)$ for different $R_{f}$ values. Two points should be noted about these results. First, the average stack temperature increases with increasing $R_{f}$ due to the recovered reactants and also the heat from downstream as described in the cell analysis section. Second, the $\partial T_{z}$ initially experiences a slight decrease followed by a steep increase after passing through a minimum. For external reforming and a well-insulated stack, the $\partial T_{z}$ can be attributed mainly to (i) different amounts of heat generated in each cell by the reaction as a function of local temperature and reactant availability, and also (ii) the amount of recycled heat to that particular cell. A minor portion can be because of differences in electrical resistance as well. The general trends in the cell average temperature profiles versus recycle rate are consistent with those of the overall fuel flow rate, which is proportional to $1 /\left(1-R_{f}\right)$, displaying the role of heat recovery inside the recycle loop on the cells' profiles. Moreover, the $\partial T_{z}$ variations can be attributed to the aforementioned phenomena, (i) and (ii), affecting the cells' temperatures, which can be further explained with the aid of the current and hydrogen profiles. For $R_{f}$ $<0.2$, both recycled heat and reaction progress contribute to the cell's temperature. For $R_{f}>0.2$, in the cell with a high fuel portion (such as Cell \#4 in Figure 8c), the temperature rise, shown in Figure 8(a), is mostly due to regained heat, since the produced current, as a function of reaction rate, does not change significantly with $R_{f}$. The average hydrogen mole fraction profile, Figure 8(b), for Cells \#4 and \#3 decline with $R_{f}$, which could negate the role of temperature in promoting the reaction progress. In contrast, the cell with lowest fuel share, Cell \#1 in particular, still benefits from both recovered heat and increased hydrogen mole fraction to drive the reaction. This is consistent with the steep current density profile for this particular cell in Figure 8(c). As a result, the $\partial T_{z}$ decreases initially to reach a minimum at $R_{f} \approx 0.42$. However, the role of recycle flow / recovered heat, that is proportional to feed share of individual cells, gradually outweighs the role of reaction heat in heating up the cells for $R_{f}>$ 0.42. This effect is more pronounced for Cells \#3 and \#4. This is actually due to the nature of mathematical relationship between amount of recycled mass and $R_{f}$. Therefore, $\partial T_{z}$ shows a considerable increase, particularly for $R_{f}>0.7$. 
With regard to current density (Figure 8c), even though trends are generally similar for different cells, the profiles show a plateau over a range of $R_{f}$ for cells with a higher feed portion, Cell \#4 in particular, while those that receive lower feed rates generate more current as $R_{f}$ increases. Therefore, increasing $R_{f}$ might either be effective or ineffective for regulating the average current output over a cell depending on its fuel flow and the $R_{f}$ value. The stacking direction gradient in currently density $\left(\partial I_{z}\right)$, however, declines over a wide range of $R_{f}$. Considering the hydrogen composition results, Figure 8(b), the impact of $R_{f}$ is interesting and shows how maldistribution problems in the stack manifold can be moderated by adjusting $R_{f}$. While hydrogen mole fraction within the cell with maximum fuel flow declines with $R_{f}$, the cell with minimum fuel flow has the hydrogen fraction increasing. Furthermore, the middle cells' profiles tend to reduce the $\partial H_{z}$. The main reason behind the hydrogen fraction decline is the dilution that occurs due to recycling a considerable amount of $\mathrm{CO}_{2}$ and $\mathrm{H}_{2} \mathrm{O}$ upstream. Moreover, hydrogen consumption also increases with $R_{f}$ as the current density profiles show. Cell \#1 exhibits different behaviour. Hydrogen concentration over the cell length (Figure 6b) is helpful to explain this observation. The fuel utilization in Cell \#1 is considerably higher than the others. Therefore the average availability of hydrogen is low, while the hydrogen fraction in the stack's outlet - that is, the sum of all cell outputs - is closer to the output of Cells \#3 and \#4 as their flow rates are much higher. Therefore, back-mixing of such a mixture dilutes the Cell \#4 and Cell \#3 anode gas. This effect is less for Cell \#2. For Cell \#1, however, recycling has a hydrogen enriching effect as Figure 8(b) shows.

With regard to the current density gradient, the positive effect of increasing $R_{f}$ on the cell's gradients has been described in the cell analysis section. In spite of this, it must be noted that for a cell with a high flow rate (Cell \#4), high $R_{f}$ is not beneficial because the trends in hydrogen and temperature, which are the main driving forces for the electrochemical reaction, oppose each other over this range, which cancels out each other's effect. This becomes more apparent when comparing the hydrogen and temperature graphs for Cell \#1, where both increase over the $R_{f}$ range, causing a progressively increasing current profile. A considerable decline of $\partial I_{z}$, in contrast, is displayed in Figure 8(c). This positive impact can be explained based on lower fuel utilisation at the stack level, which is discussed in following.

An important result from the previous section is the reduction of $\partial I_{z}$ with $R_{f}$. This positive impact can be explained based on the lower fuel utilisation at the stack level with increasing $R_{f}$, while the whole system fuel utilisation shows improvement, which is desired. The fuel utilization of the stack and the entire system are calculated by using equations (2) and (3), respectively: 


$$
\begin{gathered}
F U_{\text {stack }}=\frac{\dot{m}_{\text {stack }}^{\text {in }} F_{H_{2}}^{\text {in }}-\dot{m}_{\text {stack }}^{\text {out }} F_{H_{2}}^{\text {out }}}{\dot{m}_{\text {stack }}^{\text {in }} F_{H_{2}}^{\text {in }}} \\
F U_{\text {system }}=\frac{\dot{m}_{\text {stack }}^{\text {in }} F_{H_{2}}^{\text {in }}-\dot{m}_{\text {stack }}^{\text {out }} F_{H_{2}}^{\text {out }}}{4 \dot{m}_{\text {system }}^{\text {in }} F_{C H_{4}}^{\text {in }}}
\end{gathered}
$$

where $F U$ is the fuel utilisation, $F$ is the mole fraction and $\dot{m}$ is the molar flow rate. The results are depicted in Figure 9.

The model results for the impact of $R_{f}$ on the overall system's fuel efficiency is consistent with the work of Peters et al. (2013). Furthermore, the recycle fraction seems to be a promising operational variable for moderating the undesirable consequences of fuel flow maldistribution in the stack's manifold. It can promote the uniformity of hydrogen concentration in different cells, while the anode gas flow rates in different cells vary due to manifold hydrodynamics.

The analyses indicate that an optimum value or range for $R_{f}$ should be selected through a trade-off procedure. While higher $R_{f}$ appears to be always beneficial for current production and system fuel utilisation, it can impact the uniformity of the current density in the cell and stack - either positively or negatively - depending on operating conditions. A similar influence has been observed for the temperature gradient. On the other hand, higher $R_{f}$ would impose a higher cost on the system by increasing equipment sizes and pressure drops. According to the results of this work, an $R_{f}$ value in range of 0.45 to 0.6 offers a reasonable gradient in stacking direction profiles and system fuel utilization. However, a comprehensive optimisation study is needed to find a more precise value of $R_{f}$ for a given process configuration, operational conditions and optimisation target of interest.

\section{Conclusions}

A multi-scale modelling strategy for a SOFC was proposed to utilise commercially available flowsheeting facilities for analysis of this complex electrochemical process. The effectiveness of the model has been previously demonstrated at compartment and cell scales in Amiri et al. (2015). This work extends and demonstrates the modelling methodology at the higher level stack and system scales. The developed model is flexible and allows investigation of the influence of BoP on the performance of the fuel cell stack. The internal profiles for key spatially distributed variables in SOFC 
cell and multi-cell stack were parametrically investigated for different operational scenarios. The modelling results show that there are some opportunities for improving the uniformity of the internal temperature and current density profiles by adjusting BoP parameters such as the AGR fraction. Moreover, with the approach demonstrated here, simulation of various fuel-air flow patterns, including co-, cross- and counter-current flow in both the cell and stack are feasible and easy. The outcome of this work can be used for establishing a 3D SOFC reactor and plant modelling library for flowsheeting purposes.

\section{Acknowledgements}

The authors would like to acknowledge the financial support of the Australian Research Council (Grant Number: LP120200622).

\section{References}

Aguiar, P., C. S. Adjiman and N. P. Brandon (2004). "Anode-supported intermediate temperature direct internal reforming solid oxide fuel cell. I: model-based steady-state performance." Journal of Power Sources 138(1-2): 120-136.

Aguiar, P., D. J. L. Brett and N. P. Brandon (2008). "Solid oxide fuel cell/gas turbine hybrid system analysis for high-altitude long-endurance unmanned aerial vehicles." International Journal of Hydrogen Energy 33(23): 7214-7223.

Amiri, A., P. Vijay, M. O. Tadé, K. Ahmed, G. D. Ingram, V. Pareek and R. Utikar (2015). "Solid oxide fuel cell reactor analysis and optimisation through a novel multi-scale modelling strategy." Computers \& Chemical Engineering 78(0): 10-23.

Ameri, M. and R. Mohammadi (2011). "Simulation of an atmospheric SOFC and gas turbine hybrid system using Aspen Plus software” International Journal of Energy Research 37(5): 412425 .

Andersson, M., J. Yuan and B. Sundén (2010). "Review on modeling development for multiscale chemical reactions coupled transport phenomena in solid oxide fuel cells." Applied Energy 87(5): 1461-1476.

Ang, S. M. C., E. S. Fraga, N. P. Brandon, N. J. Samsatli and D. J. L. Brett (2011). "Fuel cell systems optimisation - Methods and strategies." International Journal of Hydrogen Energy 36(22): 14678-14703.

Bertoldi, M., T. Zandonella, V. A. C. Haanappel, J. Mertens, J. Remmel and L. G. J. de Haart (2008). "Demonstration of a 4-Cells SOFC Stack Under Different Experimental Conditions." Journal of Fuel Cell Science and Technology 5(1): 011004-011004.

Braun, R. J. (2010). "Techno-Economic Optimal Design of Solid Oxide Fuel Cell Systems for Micro-Combined Heat and Power Applications in the U.S." Journal of Fuel Cell Science and Technology 7(3): 031018-031018. 
Burt, A. C., I. B. Celik, R. S. Gemmen and A. V. Smirnov (2004). "A numerical study of cell-to-cell variations in a SOFC stack." Journal of Power Sources 126(1-2): 76-87.

Danilov, V. A., P. Vijay and M. O. Tade (2011). "Improved Tank in Series Reactor Model for Tubular Solid Oxide Fuel Cell Stacks." Chemical Engineering \& Technology 34(5): 737745 .

Di Carlo, A., D. Borello and E. Bocci (2013). "Process simulation of a hybrid SOFC/mGT and enriched air/steam fluidized bed gasifier power plant." International Journal of Hydrogen Energy 38(14): 5857-5874.

Doherty, W., A. Reynolds and D. Kennedy (2010). "Computer simulation of a biomass gasificationsolid oxide fuel cell power system using Aspen Plus.” Energy 35(12): 4545-4555.

Fermeglia, M., A. Cudicio, G. DeSimon, G. Longo and S. Pricl (2005). "Process Simulation for Molten Carbonate Fuel Cells." Fuel Cells 5(1): 66-79.

Gandiglio, M., A. Lanzini, M. Santarelli and P. Leone (2014). "Design and Balance-of-Plant of a Demonstration Plant With a Solid Oxide Fuel Cell Fed by Biogas From Waste-Water and Exhaust Carbon Recycling for Algae Growth." Journal of Fuel Cell Science and Technology 11(3): 031003-031003.

Hosseini, S., V. A. Danilov, P. Vijay and M. O. Tadé (2010). "Improved Tank in Series Model for the Planar Solid Oxide Fuel Cell." Industrial \& Engineering Chemistry Research 50(2): 1056-1069.

Iwata, M., T. Hikosaka, M. Morita, T. Iwanari, K. Ito, K. Onda, Y. Esaki, Y. Sakaki and S. Nagata (2000). "Performance analysis of planar-type unit SOFC considering current and temperature distributions." Solid State Ionics 132(3-4): 297-308.

Kivisaari, T., P. Björnbom and C. Sylwan (2002). "Studies of biomass fuelled MCFC systems." Journal of Power Sources 104(1): 115-124.

Kivisaari, T., P. C. van der Laag and A. Ramsköld (2001). "Benchmarking of chemical flowsheeting software in fuel cell applications." Journal of Power Sources 94(1): 112-121.

Liese, E. A. and R. S. Gemmen (2005). "Performance Comparison of Internal Reforming Against External Reforming in a Solid Oxide Fuel Cell, Gas Turbine Hybrid System." Journal of Engineering for Gas Turbines and Power 127(1): 86-90.

Nikooyeh, K., A. A. Jeje and J. M. Hill (2007). "3D modeling of anode-supported planar SOFC with internal reforming of methane." Journal of Power Sources 171(2): 601-609.

Park, J. and J. Bae (2011). "Parallel Manifold Effects on the Heat and Mass Transfer Characteristics of Metal-Supported Solid Oxide Fuel Cell Stacks." Journal of Fuel Cell Science and Technology 8(6): 061016-061016.

Peters, R., R. Deja, L. Blum, J. Pennanen, J. Kiviaho and T. Hakala (2013). "Analysis of solid oxide fuel cell system concepts with anode recycling." International Journal of Hydrogen Energy 38(16): 6809-6820. 
Riensche, E., J. Meusinger, U. Stimming and G. Unverzagt (1998a). "Optimization of a $200 \mathrm{~kW}$ SOFC cogeneration power plant. Part II: variation of the flowsheet." Journal of Power Sources 71(1-2): 306-314.

Riensche, E., U. Stimming and G. Unverzagt (1998b). "Optimization of a $200 \mathrm{~kW}$ SOFC cogeneration power plant: Part I: Variation of process parameters." Journal of Power Sources 73(2): 251-256.

Secanell, M., J. Wishart and P. Dobson (2011). "Computational design and optimization of fuel cells and fuel cell systems: A review." Journal of Power Sources 196(8): 3690-3704.

Wang, J. (2008). "Pressure drop and flow distribution in parallel-channel configurations of fuel cells: U-type arrangement." International Journal of Hydrogen Energy 33(21): 6339-6350.

Wang, J. (2011). "Theory of flow distribution in manifolds." Chemical Engineering Journal 168(3): $1331-1345$.

Yan, Z., P. Zhao, J. Wang and Y. Dai (2013). "Thermodynamic analysis of an SOFC-GT-ORC integrated power system with liquefied natural gas as heat sink." International Journal of Hydrogen Energy 38(8): 3352-3363.

Yuan, P. (2008). "Effect of inlet flow maldistribution in the stacking direction on the performance of a solid oxide fuel cell stack." Journal of Power Sources 185(1): 381-391.

Yuan, Z., Y. Zhang, J. Leng, Y. Gao and X. Liu (2012). "Development of a 4-cell air-breathing micro direct methanol fuel cell stack." Journal of Power Sources 202(0): 134-142.

Zhang, W., E. Croiset, P. L. Douglas, M. W. Fowler and E. Entchev (2005). "Simulation of a tubular solid oxide fuel cell stack using Aspen Plus ${ }^{\mathrm{TM}}$ unit operation models." Energy Conversion and Management 46(2): 181-196.

Zitney, S. E. (2006). "CAPE-OPEN integration for advanced process engineering co-simulation". AIChE 2006 Annual Meeting, November 12-17, San Francisco, CA.

Zitney S. E., M. T. Prinkey, M. Shahnam and W. A. Rogers (2004). "Coupled CFD and process simulation of a fuel cell auxiliary power unit". Proceedings of Fuelcell2004, The $2^{\text {nd }}$ International Conference on Fuel Cell Science, Engineering and Technology, June 14-16, 2004, Rochester, New York, USA, pp. 339-345; doi:10.1115/FUELCELL2004-2490. 
Table 1: Comparison of modelling features of some fuel cell flowsheeting studies.

\begin{tabular}{|c|c|c|c|c|c|c|c|}
\hline Feature & $\begin{array}{l}\text { Zitney } \\
\text { et al. } \\
(2004)\end{array}$ & $\begin{array}{c}\text { Ameri and } \\
\text { Mohammadi } \\
(2011)\end{array}$ & $\begin{array}{l}\text { Kivisaari } \\
\text { et al. } \\
(2002) \\
\end{array}$ & $\begin{array}{c}\text { Doherty } \\
\text { et al. } \\
(2010)\end{array}$ & $\begin{array}{c}\text { Fermeglia } \\
\text { et al. } \\
(2005) \\
\end{array}$ & $\begin{array}{c}\text { Zhang } \\
\text { et al. } \\
(2005)\end{array}$ & $\begin{array}{c}\text { This } \\
\text { work }^{+}\end{array}$ \\
\hline \multicolumn{8}{|l|}{ Model Dimensions } \\
\hline 0D/lumped & $*$ & $*$ & $*$ & $*$ & $*$ & $*$ & $*$ \\
\hline $1 \mathrm{D}$ & $*$ & - & - & - & $*$ & - & $*$ \\
\hline $2 \mathrm{D}$ & $*$ & - & - & - & $*$ & - & $*$ \\
\hline $3 \mathrm{D}$ & - & - & - & - & - & - & $*$ \\
\hline \multicolumn{8}{|l|}{ Simulation Mode } \\
\hline Steady State & $*$ & $*$ & $*$ & $*$ & $*$ & $*$ & $*$ \\
\hline Dynamic & - & - & - & - & $\mathrm{C}$ & - & $\mathrm{C}$ \\
\hline \multicolumn{8}{|l|}{ Scales Considered } \\
\hline Compartment & - & $*$ & $*$ & $*$ & $*$ & $*$ & $*$ \\
\hline Cell & $*$ & - & - & - & $*$ & - & $*$ \\
\hline Stack/multilayer & - & - & - & - & - & - & $*$ \\
\hline System/BoP & $*$ & $*$ & $*$ & $*$ & $*$ & $*$ & $*$ \\
\hline \multicolumn{8}{|l|}{ Transport Phenomena } \\
\hline Mass transfer & - & - & - & - & $*$ & - & $*$ \\
\hline Heat transfer & - & - & - & - & $*$ & - & $*$ \\
\hline \multicolumn{8}{|l|}{ Fuel-Air Flow pattern } \\
\hline Co-Flow & - & - & - & - & - & - & $*$ \\
\hline Counter-Flow & - & - & - & - & - & - & $*$ \\
\hline Cross-Flow & - & - & - & - & - & - & $*$ \\
\hline \multicolumn{8}{|l|}{ Stacking Issues } \\
\hline Manifold effect & - & - & - & - & - & - & $*$ \\
\hline Cell-to-cell effect & - & - & - & - & - & - & - \\
\hline \multicolumn{8}{|l|}{ Process Analysis } \\
\hline Sensitivity & $*$ & $*$ & $*$ & $*$ & $*$ & $*$ & $*$ \\
\hline Optimisation & - & - & - & - & - & - & $*$ \\
\hline
\end{tabular}

(*) Considered, (-) Not considered, (C) Presented for the compartment scale only, (+) Some features are presented in Amiri et al. (2015). 
Table 2: Process simulation input parameters for base case.

\begin{tabular}{|c|c|c|}
\hline Parameter & \multicolumn{2}{|c|}{ Value } \\
\hline Main streams & \multirow{2}{*}{\multicolumn{2}{|c|}{$8 \times 10^{-4}$}} \\
\hline 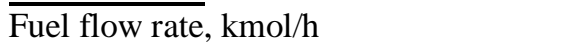 & & \\
\hline Fuel inlet pressure, atm & \multicolumn{2}{|c|}{2} \\
\hline \multicolumn{3}{|l|}{ Fuel composition, mole fraction } \\
\hline Methane, $\mathrm{CH}_{4}$ & \multicolumn{2}{|c|}{0.830} \\
\hline Ethane, $\mathrm{C}_{2} \mathrm{H}_{6}$ & \multicolumn{2}{|c|}{0.020} \\
\hline Propane, $\mathrm{C}_{3} \mathrm{H}_{8}$ & \multicolumn{2}{|c|}{0.016} \\
\hline Normal butane, $\mathrm{n}-\mathrm{C}_{4} \mathrm{H}_{10}$ & \multicolumn{2}{|c|}{0.001} \\
\hline Carbon monoxide, $\mathrm{CO}$ & \multicolumn{2}{|c|}{0.001} \\
\hline Carbon dioxide, $\mathrm{CO}_{2}$ & \multicolumn{2}{|c|}{0.001} \\
\hline Hydrogen, $\mathrm{H}_{2}$ & \multicolumn{2}{|c|}{0.000} \\
\hline Water, $\mathrm{H}_{2} \mathrm{O}$ & \multicolumn{2}{|c|}{0.001} \\
\hline Nitrogen, $\mathrm{N}_{2}$ & \multicolumn{2}{|c|}{0.130} \\
\hline Oxygen, $\mathrm{O}_{2}$ & \multicolumn{2}{|c|}{0.000} \\
\hline Air flow rate, $\mathrm{kmol} / \mathrm{h}$ & \multicolumn{2}{|c|}{$8.8 \times 10^{-3}$} \\
\hline Air inlet pressure, atm & \multicolumn{2}{|c|}{2} \\
\hline \multicolumn{3}{|l|}{ Air composition, mole fraction } \\
\hline Nitrogen, $\mathrm{N}_{2}$ & \multicolumn{2}{|c|}{0.790} \\
\hline Oxygen, $\mathrm{O}_{2}$ & \multicolumn{2}{|c|}{0.210} \\
\hline \multicolumn{3}{|l|}{ Reformer } \\
\hline Reformer temperature, $\mathrm{K}$ & \multicolumn{2}{|c|}{1073} \\
\hline Reformer pressure, atm & \multicolumn{2}{|c|}{1} \\
\hline \multicolumn{3}{|l|}{ Fuel cell stack } \\
\hline Number of cells & \multirow{2}{*}{\multicolumn{2}{|c|}{$\begin{array}{c}4 \\
\text { Co-flow }\end{array}$}} \\
\hline Cell flow pattern & & \\
\hline Cell voltage, $\mathrm{V}$ & \multicolumn{2}{|c|}{0.80} \\
\hline Pressure drop, atm & \multicolumn{2}{|c|}{0.05} \\
\hline Fuel cell compartment & Cathode & Anode \\
\hline$\overline{\text { Catalyst width } \delta, \mathrm{m}}$ & $2.5 \times 10^{-4}$ & $3 \times 10^{-5}$ \\
\hline Porosity $\varepsilon$ & 0.4 & 0.4 \\
\hline Charge transfer coefficient $\alpha_{A}$ & 2 & 1.4 \\
\hline Charge transfer coefficient $\alpha_{C}$ & 1 & 0.6 \\
\hline Channel height, $\mathrm{m}$ & \multicolumn{2}{|c|}{$7.5 \times 10^{-4}$} \\
\hline Section area, $\mathrm{m}^{2}$ & \multicolumn{2}{|c|}{$3.5 \times 10^{-4}$} \\
\hline Electrolyte width, m & \multirow{2}{*}{\multicolumn{2}{|c|}{$\begin{array}{c}1 \times 10^{-5} \\
106\end{array}$}} \\
\hline PEN thermal capacity $\rho c_{p}^{P E N}, \mathrm{~J} \mathrm{~m}^{-3} \mathrm{~K}^{-1}$ & & \\
\hline
\end{tabular}




\section{Figures' Captions}

Figure 1: Multi-scale modelling roadmap and software interactions (Amiri et al., 2015).

Figure 2: Process flowsheet of a SOFC plant with a 3D fuel cell stack modelled in Aspen Plus.

Figure 3: Cell temperature profiles for a range of recycle fractions: (a) Reformer $T=973 \mathrm{~K}$ and (b) Reformer $T=1073 \mathrm{~K}$.

Figure 4: Cell hydrogen mole fraction profiles for a range of recycle fractions: (a) Reformer $\mathrm{T}=$ $973 \mathrm{~K}$ and (b) Reformer T $=1073 \mathrm{~K}$.

Figure 5: Cell current density profiles for a range of recycle fractions: (a) Reformer $\mathrm{T}=973 \mathrm{~K}$ and (b) Reformer $\mathrm{T}=1073 \mathrm{~K}$.

Figure 6: Distributions of key variables in the $x$ direction due to maldistribution of flow in the fuel manifold for a recycle fraction of $R_{f}=0.5$ : (a) temperature, (b) hydrogen mole fraction and (c) current density. The case of uniform fuel distribution is shown by line marked "Equal Flow".

Figure 7: Local gradient of key variables in stacking (z) direction due to maldistribution of flow in the fuel manifold for a recycle fraction of $\mathrm{R}_{\mathrm{f}}=0.5$ : (a) temperature, (b) hydrogen mole fraction and (c) current density. "Upper Half" refers to gradient between Cell \#1 and Cell \#2, and "Lower Half" refers to the gradient between Cell \#3 and Cell \#4.

Figure 8: Effect of recycle fraction $R_{f}$ on the average values of key variables in each cell and their gradients in the stacking (z) direction (difference between top and bottom of stack): (a) temperature, (b) hydrogen mole fraction, and (c) current density.

Figure 9: Effect of recycle fraction on stack and system fuel utilisation. 


\section{Highlights}

- SOFC system is simulated through a detailed user-defined electrochemical reactor;

- Manifold maldistribution is assessed in process flowsheeting environment;

- Role-playing internal gradients are modelled for a multilayer stack;

- Potential impact of anode gas recycling on cell and stack internal gradients and efficiencies is analysed. 


\section{Compartment Scale $(1 \mu \mathrm{m}-1 \mathrm{~cm})$}

\section{Typical Issues}

- Reaction kinetics, heat and mass transfer

- Fuel conversion, carbon deposition

- Catalyst and material improvements

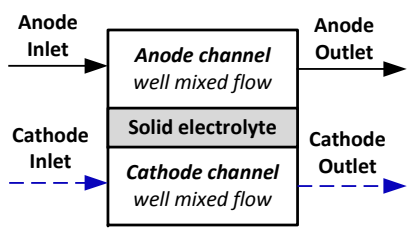

\section{Channel Scale $(1 \mathrm{~cm}-10 \mathrm{~cm})$}

Typical Issues

- Fuel and air flow configuration

- Fluid flow regimes

- Residence time distributions

Fresh Fuel

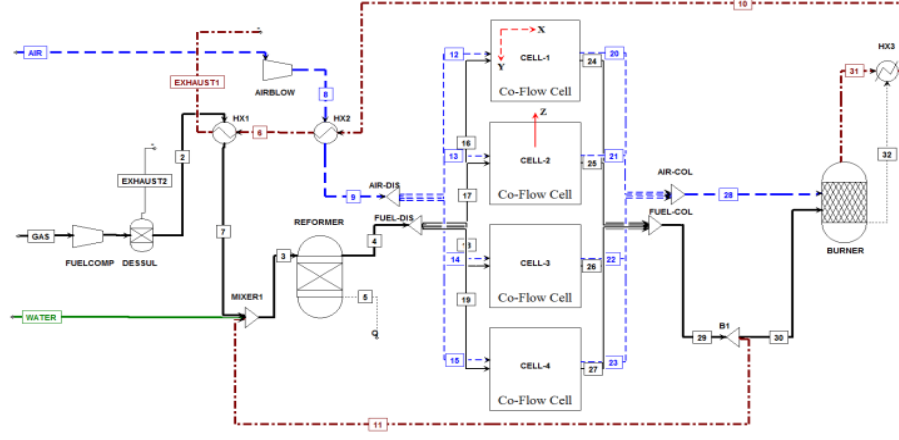

Modelling communication framework

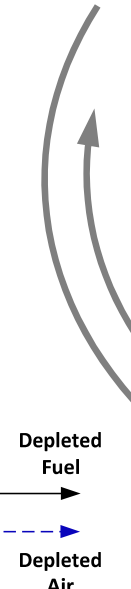

Aspen Custom Modeller

- Modelling and programming

- Single element dynamic analysis

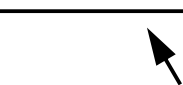

Aspen Properties

- Component properties

- Fluid package(s)

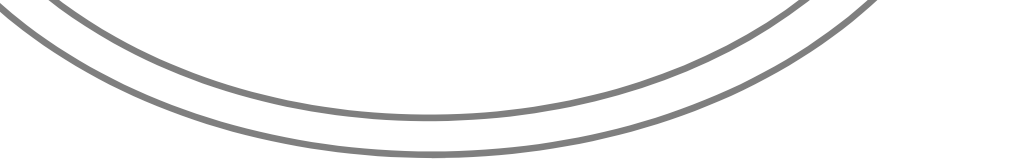

System Scale $(1 \mathrm{~m}-10 \mathrm{~m})$ Typical Issues

- Process optimisation

- Process dynamics and control

- Process commercialisation

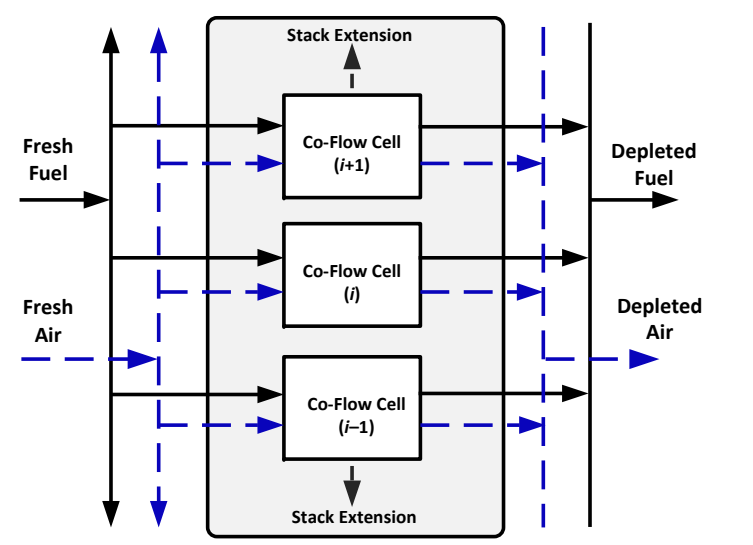

\section{Stack Scale $\quad(10 \mathrm{~cm}-1 \mathrm{~m})$} Typical Issues

- Stack energy integration

- Process steadiness

- Start-up and shut-down dynamics

Cell Scale $(1 \mathrm{~cm}-10 \mathrm{~cm})$ Typical Issues

- Thermal management

- Cell life durability

- Dynamic cell behaviour

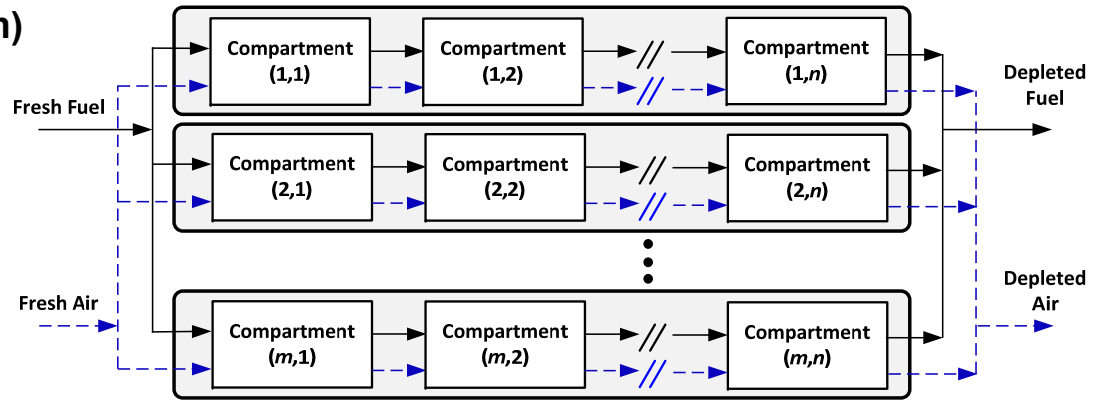




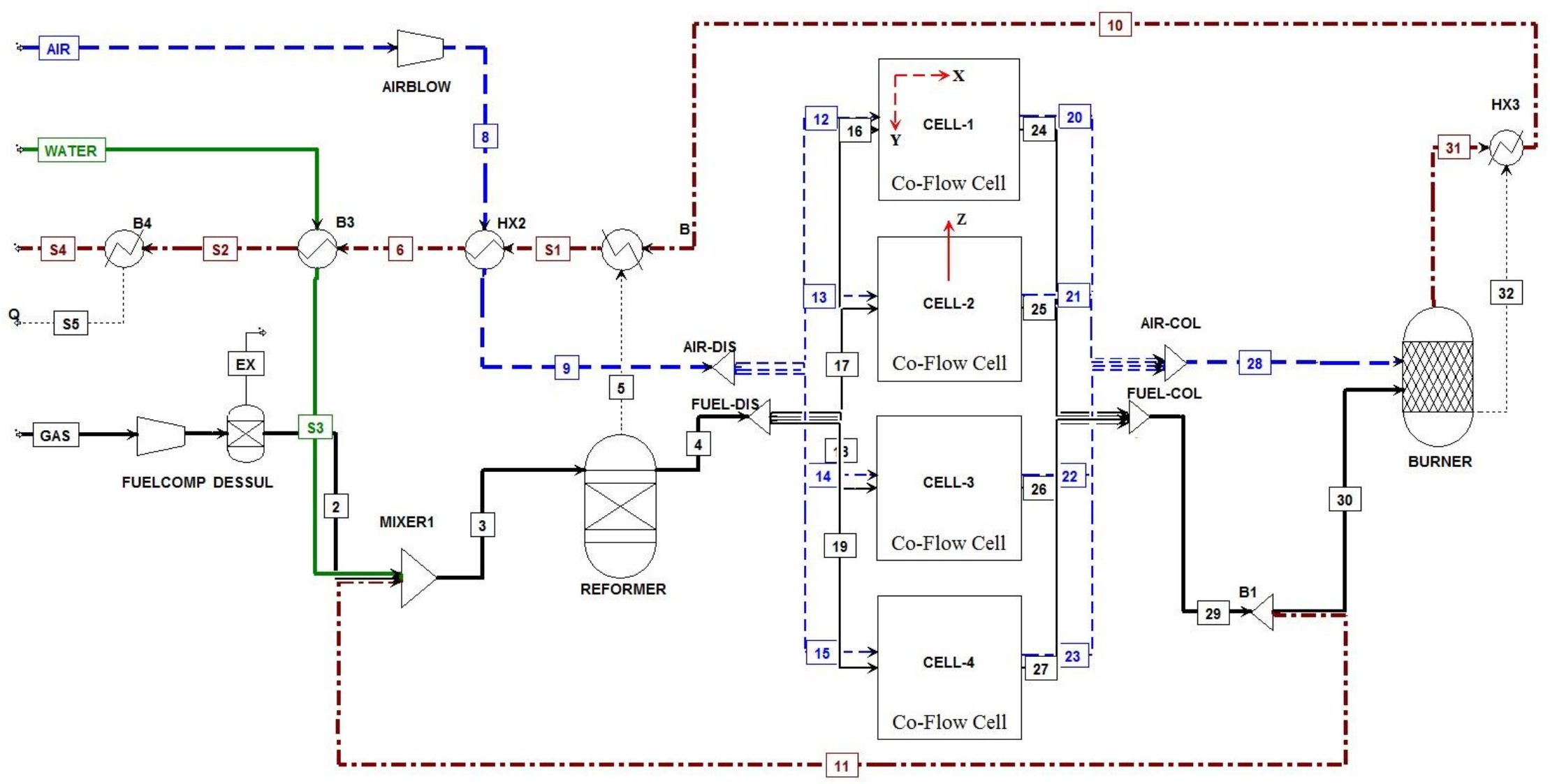

Figure 2: Process flowsheet of a SOFC plant with a 3D fuel cell stack modelled in Aspen Plus. 

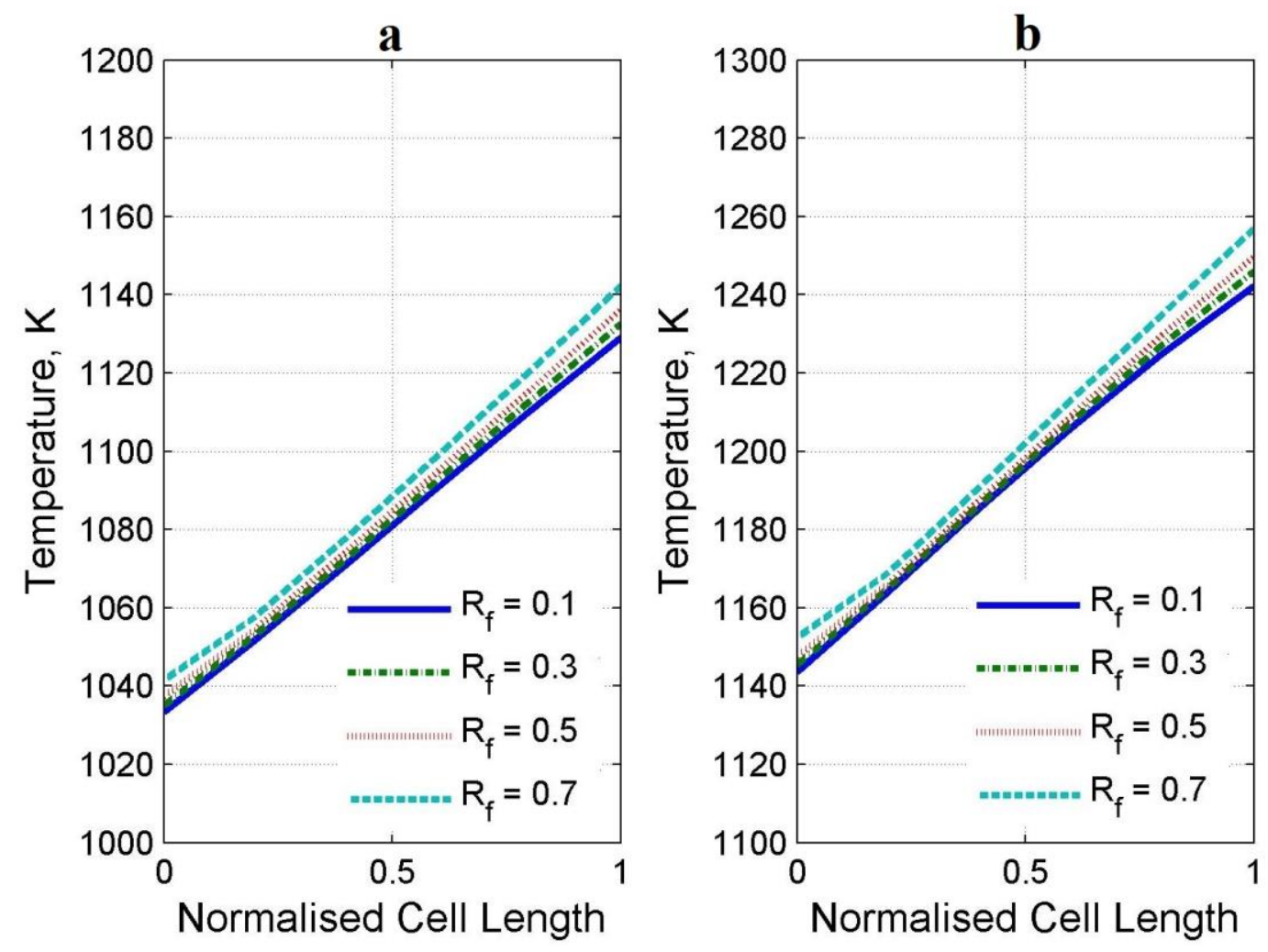

Figure 3: Cell temperature profiles for a range of recycle fractions: (a) Reformer $T=$ $973 \mathrm{~K}$ and (b) Reformer $T=1073 \mathrm{~K}$. 

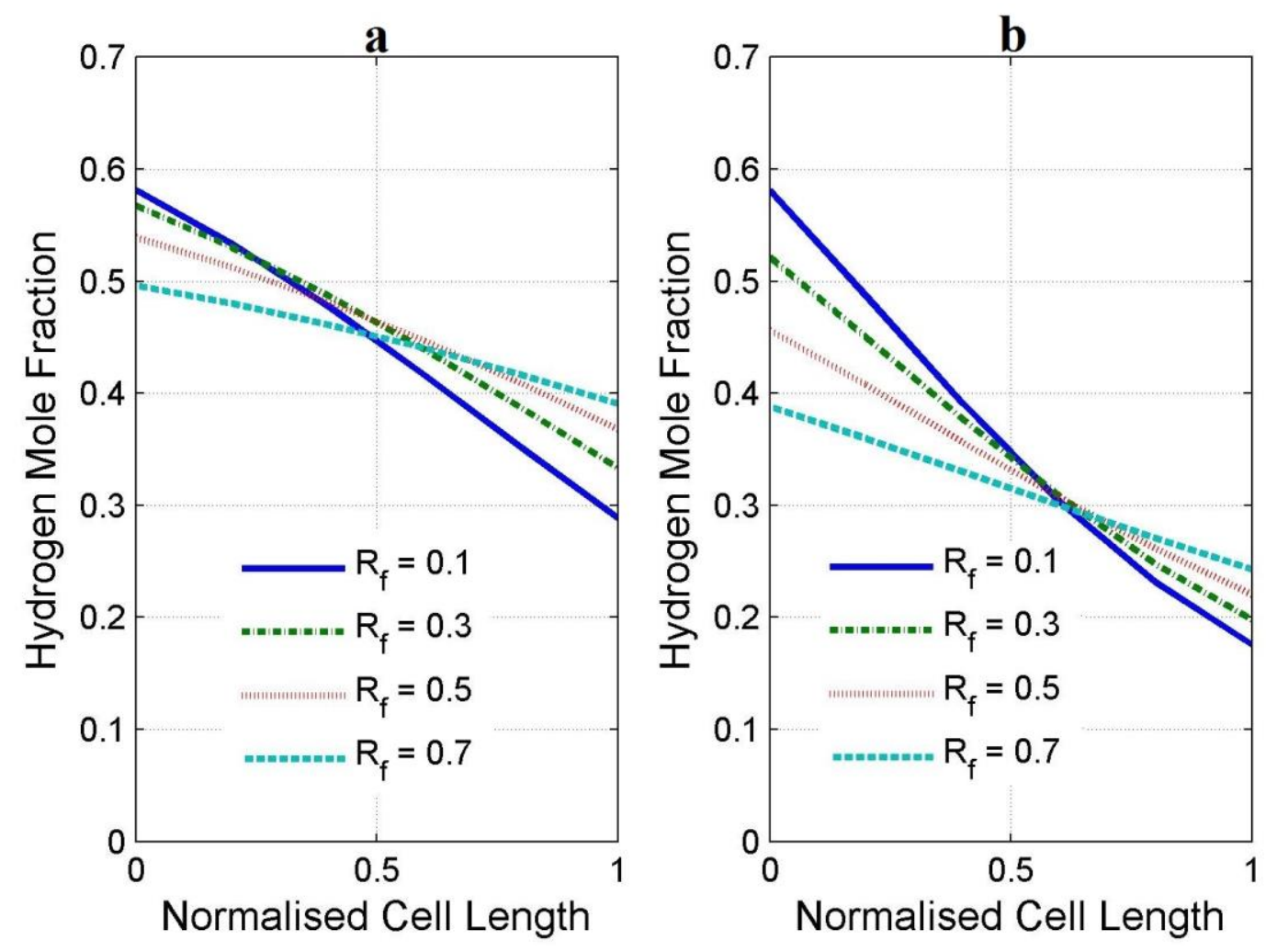

Figure 4: Cell hydrogen mole fraction profiles for a range of recycle fractions: (a) Reformer $\mathrm{T}=973 \mathrm{~K}$ and $(\mathrm{b})$ Reformer $\mathrm{T}=1073 \mathrm{~K}$. 

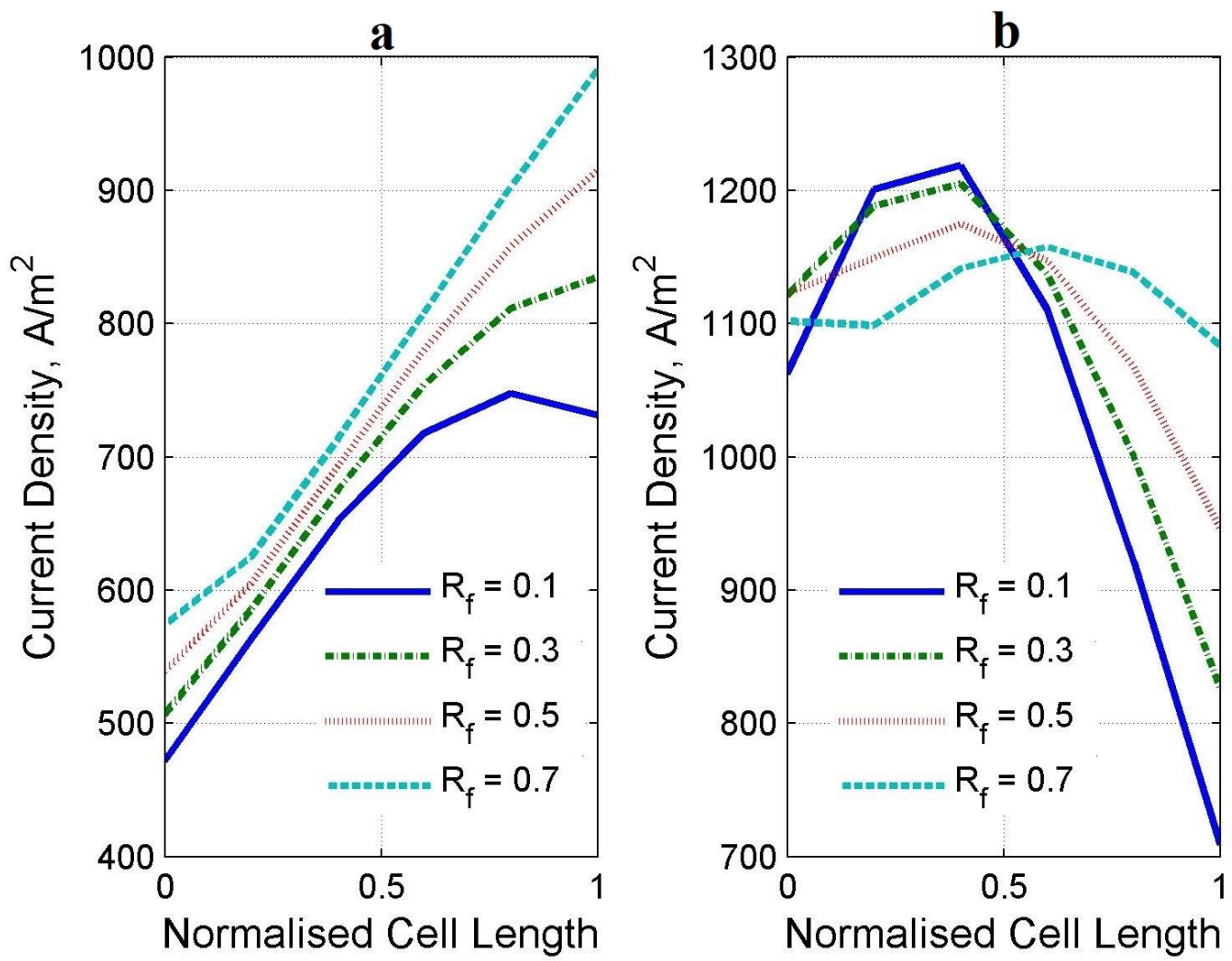

Figure 5: Cell current density profiles for a range of recycle fractions: (a) Reformer T $=973 \mathrm{~K}$ and $(\mathrm{b})$ Reformer $\mathrm{T}=1073 \mathrm{~K}$. 

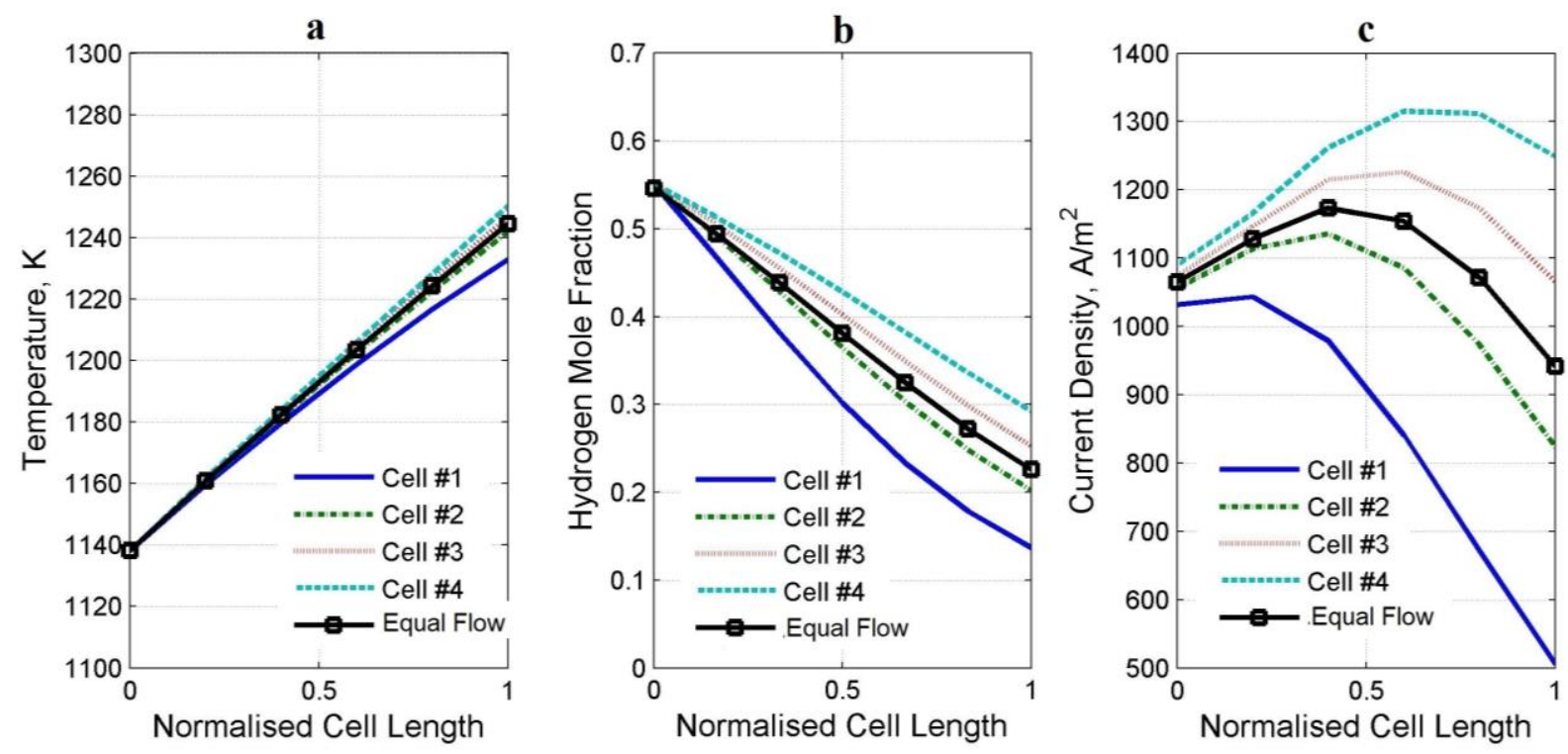

Figure 6: Distributions of key variables in the $x$ direction due to maldistribution of flow in the fuel manifold for a recycle fraction of $R_{f}=0.5$ : (a) temperature, (b) hydrogen mole fraction and (c) current density. The case of uniform fuel distribution is shown by line marked "Equal Flow". 

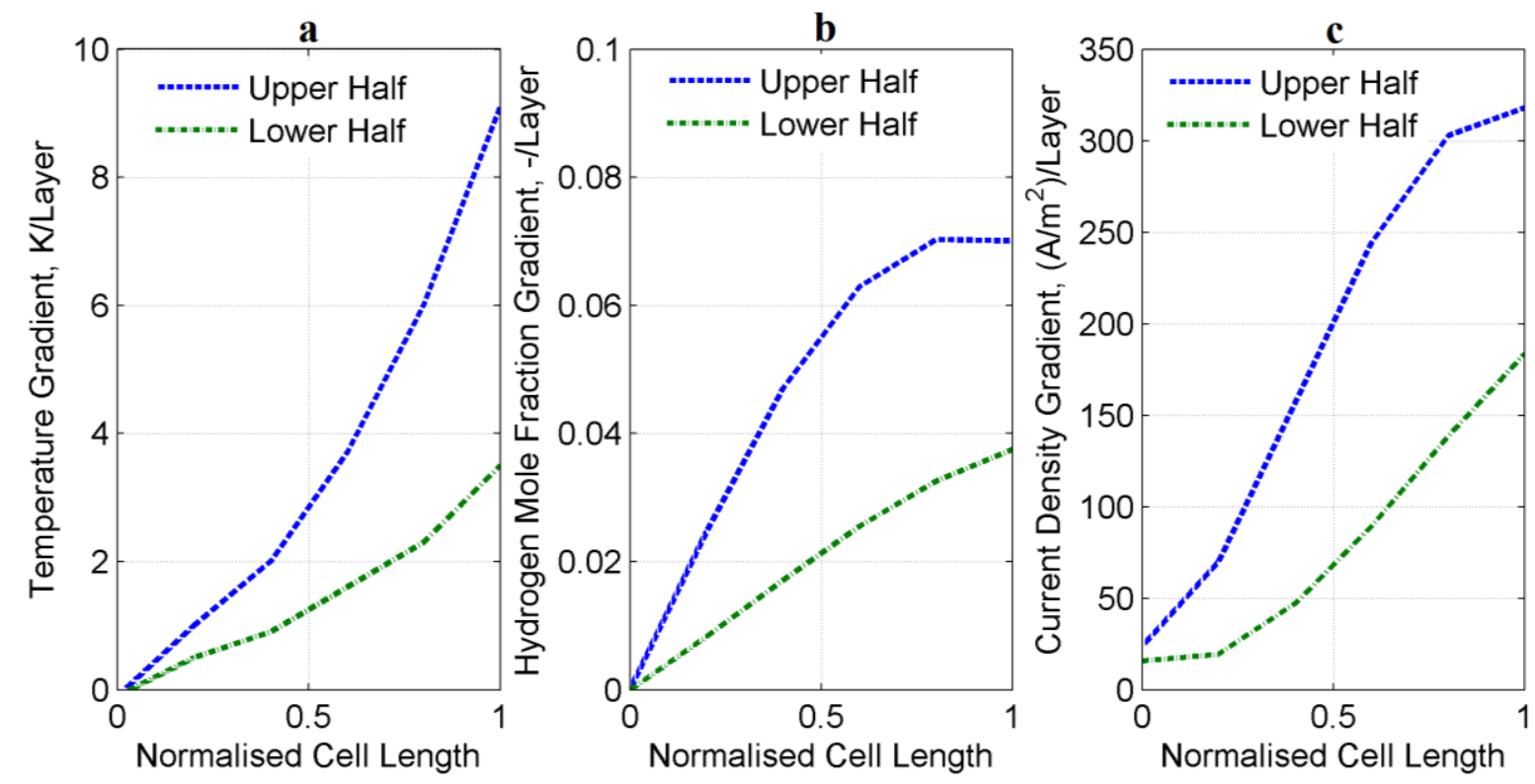

Figure 7: Local gradient of key variables in stacking (z) direction due to maldistribution of flow in the fuel manifold for a recycle fraction of $R_{f}=0.5$ : (a) temperature,

(b) hydrogen mole fraction and (c) current density. "Upper Half" refers to gradient between Cell \#1 and Cell \#2, and "Lower Half" refers to the gradient between Cell \#3 and Cell \#4. 

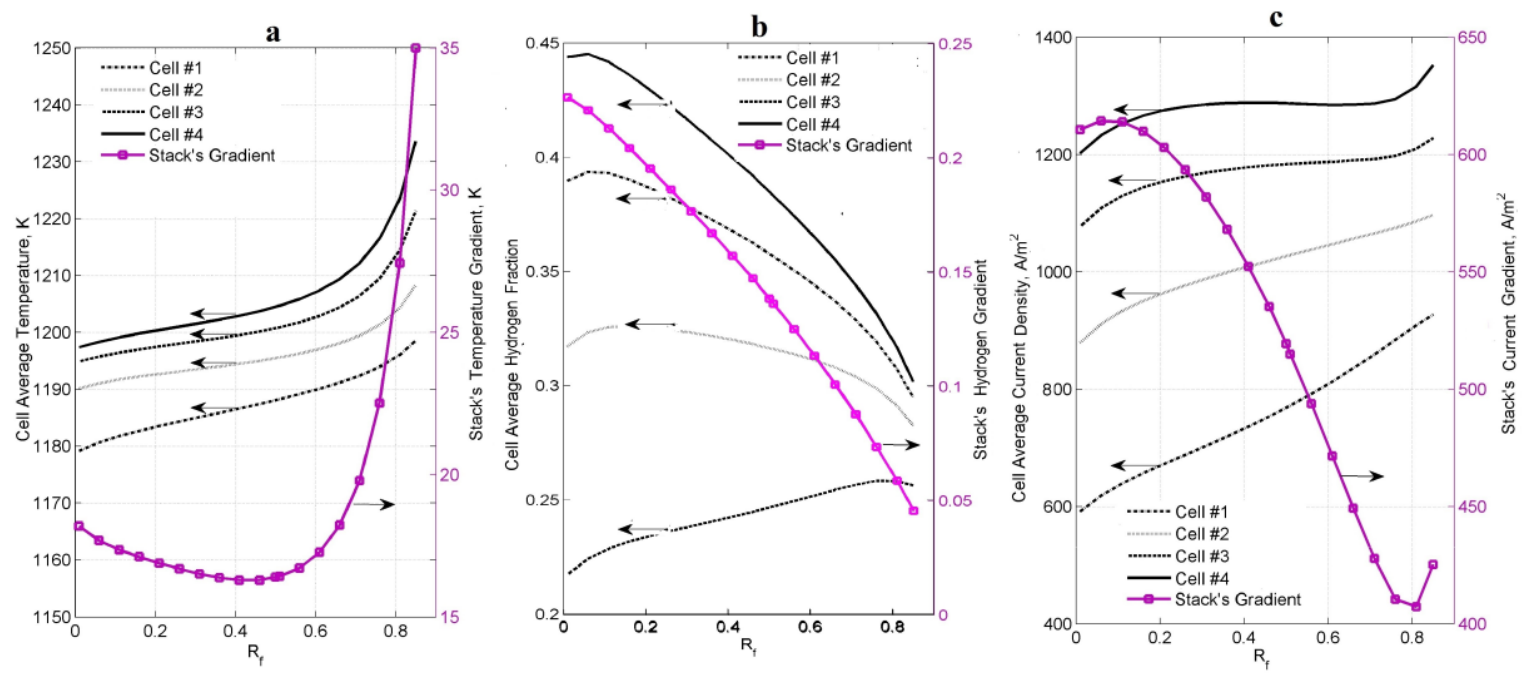

Figure 8: Effect of recycle fraction $R_{f}$ on the average values of key variables in each cell and their gradients in the stacking ( $\mathrm{z}$ ) direction (difference between top and bottom of stack): (a) temperature, (b) hydrogen mole fraction, and (c) current density. 


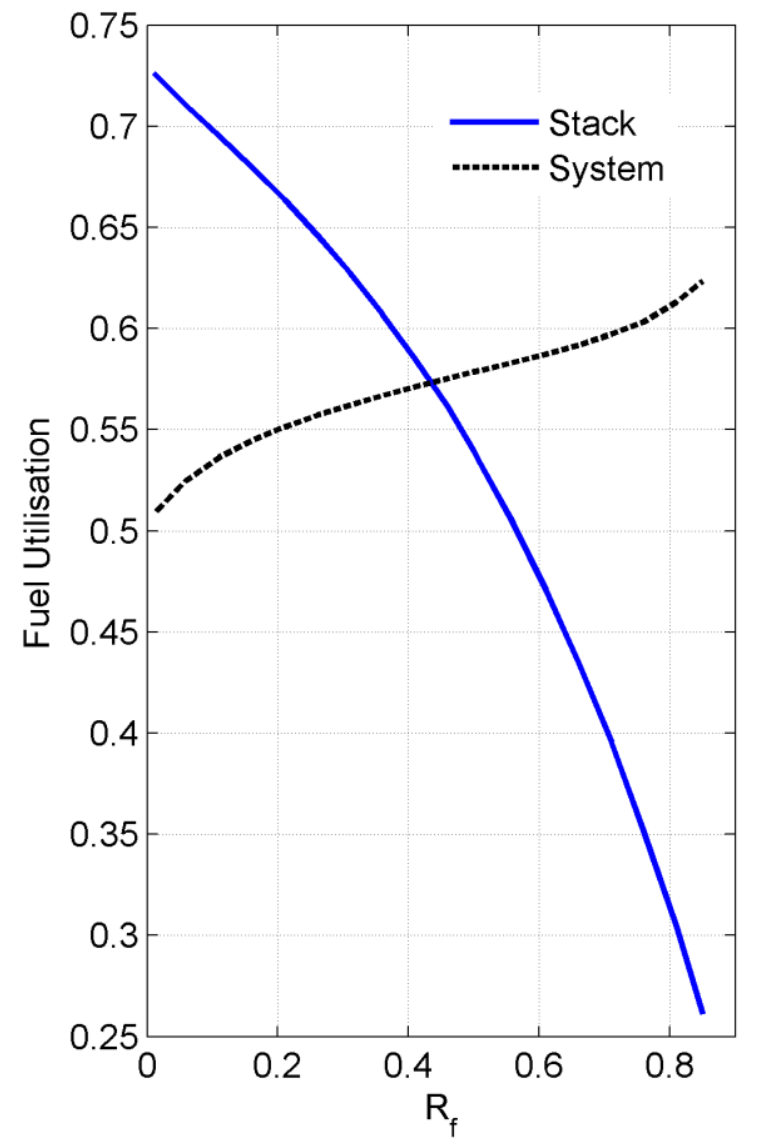

Figure 9: Effect of recycle fraction on stack and system fuel utilisation. 